\title{
Hybrid Drying of Carrot Preliminary Processed with Ultrasonically Assisted Osmotic Dehydration
}

\author{
Dominik Mierzwa*, Stefan Jan Kowalski and Joanna Kroehnke \\ Poznań University of Technology, Department of Process Engineering, Institute of Technology and \\ Chemical Engineering, ul. Berdychowo 4, PL-60-965 Poznań, Poland
}

Received: August 9, 2016

Accepted: February 22, 2017

\begin{abstract}
Summary
In this paper the kinetics of osmotic dehydration of carrot and the influence of this pretreatment on the post-drying processes and the quality of obtained products are analysed. Osmotic dehydration was carried out in the aqueous fructose solution in two different ways: with and without ultrasound assistance. In the first part of the research, the kinetics of osmotic dehydration was analysed on the basis of osmotic dewatering rate, water loss and solid gain. Next, the effective time of dehydration was determined and in the second part of research samples were initially dehydrated for $30 \mathrm{~min}$ and dried. Five different procedures of drying were established on the grounds of convective method enhanced with microwave and infrared radiation. The influence of osmotic dehydration on the drying kinetics and final product quality was analysed. It was found that it did not influence the drying kinetics significantly but positively affected the final product quality. Negligible influence on the drying kinetics was attributed to solid uptake, which may block the pores, hindering heat and mass transfer. It was also concluded that the application of microwave and/or infrared radiation during convective drying significantly influenced the kinetics of the final stage of drying. A proper combination of aforementioned techniques of hybrid drying allows reducing the drying time. Differences between the particular dehydration methods and drying schedules were discussed.
\end{abstract}

Key words: osmotic dehydration, ultrasound, microwaves, hybrid drying, dry product colour

\section{Introduction}

Drying is one of the most commonly used preservation methods of perishable products such as fruit and vegetables. This process allows stabilising the raw material by reducing the moisture content and water activity, which are responsible for most of the natural decay processes. Unfortunately, almost every drying technique adversely affects the product quality, reducing its value. The type and degree of product quality change depend on the drying method and process parameters such as temperature and humidity of the drying agent, the velocity of air flow, duration and power of microwaves, infrared or ul- trasound enhancement, etc. For example, in the case of the most popular convective (hot air) drying, the high temperature and long process time induce a series of chemical and biochemical conversions resulting in a change of colour, taste, aroma and nutrient properties (1-4). Moreover, excessive shrinkage or shape deformation usually occur (5-7), making the product unappealing to the customer.

The energy consumption is another problem relevant in drying. The drying has been recognised as one of the most energy-intensive unit operations, which exploits up to $25 \%$ of all industrial energy usage $(8,9)$. Because of re- 
cent environmental and power engineering problems, i.e. abatement of greenhouse gas emissions, depletion of fossil fuels, etc. (10), it has become extremely important to reduce the consumption of energy in all industrial sectors. For these reasons, alternative methods of pretreatment and drying are sought to produce high-quality products at the possibly minimum capital and operating costs (10-12).

One of the most promising methods of pretreatment applied before essential drying operation is the osmotic dehydration. It is a non-thermal process that utilises the phenomenon of osmosis, occurring after immersion of the plant tissue in hypertonic aqueous solution (e.g. sugar or salt solution). The difference in water activity and osmotic pressure between plant tissue and ambient hypertonic solution promotes two oppositely directed fluxes. Water permeates through the cell membrane from the plant tissue to the solution, while soluble solids penetrate the cell wall from the solution to the interior of the plant cell $(13,14)$. In this way, even $50 \%$ of water initially present in the material can be removed at a relatively low expenditure of energy $(15,16)$. According to Lewicki and Lenart (17), convective drying needs about $5 \mathrm{MJ}$ per $\mathrm{kg}$ of evaporated water, whereas osmotic dehydration needs only 0.1-2.4 MJ per kg of removed water. Moreover, due to low operating temperatures, osmotic pretreatment enables the drying of thermosensitive products and improves the final product quality.

Because of diffusional character, the osmosis processes are usually very slow (especially at low temperatures) and limited by equilibrium state. To increase the efficiency of the osmotic dehydration, these processes are increasingly aided by power ultrasound with the intensity above $1 \mathrm{~W} / \mathrm{cm}^{2}$ and frequency around $21-25 \mathrm{kHz}(18,19)$. Higher frequencies are not recommended due to the increase of energy absorption by the solution and, as a consequence, reduction of penetration depth into the processed material (20). Nevertheless, application of ultrasound during osmotic pretreatment allows the increase of water diffusion coefficient and enhancement of dewatering rate.

The influence of the ultrasonic waves on the kinetics of osmosis has not been fully investigated. It is assumed that one of the mechanisms causes a series of rapid alternate compression and expansion movements in a similar way to sponge when it is squeezed and released repeatedly. This 'sponge effect' reduces the thickness of the diffusion boundary layer and leads to an increase of the mass transfer coefficients. The forces involved in cyclic ultrasonic waves can be much greater than those that arise from surface tension holding the moisture inside the capillaries. Moreover, ultrasonic waves usually induce cavitation phenomenon, which allows the removal of moisture bound to the solid matrix $(21,22)$. Last but not least, it was also proven that the application of ultrasonic waves during osmotic dehydration contributes to a reduction of microbiological contamination of raw material $(23,24)$.

The appearance of fresh and processed food products is one of the most important sensory quality attributes. It is also worth noticing that colour of the product surface is the first quality parameter evaluated by consumers, and it is critical to product acceptance (25-27). Colour is the first sensation that the consumers perceive, thus it has a strong influence on their opinion about the food quality (28). In the absence of any other generally available tools, the customer is willing to either accept or reject a presented food product based only on visual stimuli associated with the colour of the product (29). Although each food product may be characterised by the acceptable colour range, its acceptability usually depends on a wide variety of factors, including variability among consumers, their age and ethnic origin, and the physical nature of the surroundings at the time of judgement (30).

The research presented in this paper aims to analyse the drying processes of carrot pretreated with osmotic dehydration or ultrasound-assisted osmotic dehydration. Three different drying techniques, namely convective, microwave and infrared were applied in five different combinations (hybrid drying) to find the most efficient preservation procedure. Such a combination often promotes synergistic effects and allows the elimination of defects attributed to individual drying techniques. The effectiveness of each schedule was analysed on the basis of drying kinetics and final product quality.

\section{Materials and Methods}

\section{Sample preparation}

Carrot (Daucus carota L. cv. Nantes) was used as the experimental material. Fresh roots were bought on the local market and stored in the refrigerator at $277.15 \mathrm{~K}\left(4^{\circ} \mathrm{C}\right)$ for at least $24 \mathrm{~h}$. Before processing, each root was stabilised for $4 \mathrm{~h}$ at a room temperature and then washed, cleaned and sliced with a ceramic knife to prevent reactions between metal and biological material. Afterwards, cylindrical samples $(35 \times 5 \mathrm{~mm}$; diameter $\times$ height $)$ were prepared with the use of polypropylene mould.

\section{Osmotic dehydration}

Osmotic dehydration was performed with the use of aqueous solutions of analytically pure fructose at the mass fraction of $400 \mathrm{~g}$ of soluble solid per $\mathrm{kg}$ of solution. The solution was prepared at a room temperature $\left(294.15 \mathrm{~K}\right.$, i.e. $21^{\circ} \mathrm{C}$ ) by mixing the predetermined mass of osmotic agent with distilled water. The solution to sample mass ratio was at least $4: 1$ to avoid the dilution effect. A given volume $(100 \mathrm{~mL})$ of the solution was poured into four transparent beakers $(600 \mathrm{~mL})$ and placed in water bath for $15 \mathrm{~min}$ to stabilise the temperature. Sixteen randomly chosen carrot slices were weighed on the laboratory balance model AJH-2200CE (precision $0.01 \mathrm{~g}$ ) produced by Vibra/Shinko Denshi (Tokyo, Japan) and then immersed in the osmotic solution (four samples per beaker).

In the first part of the research, the kinetics of two types of osmotic dehydration processes, namely with and without ultrasound assistance, were analysed. For this purpose, samples were dewatered in osmotic solution for $120 \mathrm{~min}$ and their mass was measured periodically in two different intervals, namely every $10 \mathrm{~min}$ for the 1 st hour and then every $15 \mathrm{~min}$ for the next hour. For weighing 
purpose, the samples were taken out from the beaker and drained gently with absorbent paper.

Each osmotic dehydration (OD) process was carried out in ultrasonic bath model IS-14S produced by Intersonic s.c. (Olsztyn, Poland) at stabilised bath temperature $T_{\mathrm{OD}}=303.15 \mathrm{~K}\left(30^{\circ} \mathrm{C}\right)$. In the case of ultrasonically-assisted osmotic dehydration (UAOD) processes, the acoustic waves of frequency $f=25 \mathrm{kHz}$ and intensity $I_{\mathrm{UAOD}}>1 \mathrm{~W} / \mathrm{cm}^{2}$ were used. To avoid the increase of the bath temperature due to the action of ultrasound and cavitation phenomenon, the working medium (water) was cooled in the internal heat exchangers, which allows maintaining a constant temperature of the bath during the research.

Kinetics and effectiveness of osmotic dehydration were assessed on the basis of solid gain (SG), water loss (WL) and osmotic dehydration rate (ODR) determined in compliance with the following equations:

$$
\begin{gathered}
\mathrm{SG}=\left(m_{\mathrm{st}}-m_{\mathrm{si}}\right) / m_{\mathrm{i}} \\
\mathrm{WL}=\left[\left(m_{\mathrm{i}}-m_{\mathrm{t}}\right)+\left(m_{\mathrm{st}}-m_{\mathrm{si}}\right)\right] / m_{\mathrm{i}} \\
\mathrm{ODR}=\mathrm{d} m / \mathrm{d} t
\end{gathered}
$$

where $m_{\mathrm{st}}$ and $m_{\mathrm{si}}$ are masses of solid matter of osmotically dehydrated and fresh (not subjected to osmotic dewatering) sample respectively, $m_{\mathrm{i}}$ is the initial mass of sample and $m_{\mathrm{t}}$ is the mass of osmotically treated sample, $\mathrm{d} m$ is the change of sample mass and $\mathrm{d} t$ is the time at which the change of mass followed. The mass of the dry matter $\left(m_{\mathrm{st}}\right.$ and $\left.m_{\mathrm{si}}\right)$ was determined after $24 \mathrm{~h}$ of drying at $\mathrm{T}=$ $348.15 \mathrm{~K}\left(75^{\circ} \mathrm{C}\right)$ in the convective dryer, model SML42/ 250/M, produced by Zalmed (Dąbrowa, Poland).

The obtained results were used to determine the most effective period of dehydration. Thus, in the second part of research, the carrot samples were dehydrated only for 30 min using both variants of the process. The sample mass was measured at the beginning and the end of the pretreatment. The dehydration efficiency was judged on the basis of solid gain and water loss.

\section{Drying operation}

The osmotically dewatered samples were subjected to final drying with the use of convective, microwave and infrared techniques according to five different procedures. A detailed description of the drying programs is given in Table 1.

The structure of the particular drying procedures was established on the basis of the authors' previous studies on hybrid drying of beetroot (31) and red pepper (32). Each drying process was carried out in the laboratory dryer constructed by ERTEC (Wrocław, Poland) described previously (31).

The following settings of drying parameters were used: air temperature $T_{\mathrm{a}}=331.15 \mathrm{~K}\left(58^{\circ} \mathrm{C}\right)$, airflow velocity $v_{\mathrm{a}}=1.6 \mathrm{~m} / \mathrm{s}$, microwave power $P_{\mathrm{MW}}=100 \mathrm{~W}$ (if used) and infrared power $P_{\mathrm{IR}}=250 \mathrm{~W}$ (if used). The relative humidity $(\mathrm{RH})$ of the air used for drying was controlled with the humidity and temperature transmitter model Hygrotest 600 DHT -20/120, produced by Testo (Lenzkirch, Germany). The air RH ranged between 20 and $22 \%$, i.e. $21 \%$ on

\begin{tabular}{|c|c|}
\hline Procedure & Description \\
\hline $\mathrm{I}$ & Convective drying \\
\hline II & $\begin{array}{l}\text { Convective drying enhanced with microwaves } \\
\text { throughout the process }\end{array}$ \\
\hline III & $\begin{array}{l}\text { Convective drying enhanced with microwaves } \\
\text { during the first } 40 \text { min of the process }\end{array}$ \\
\hline IV & $\begin{array}{l}\text { Convective drying enhanced with microwaves after } \\
\text { the } 120 \text { th min of the process }\end{array}$ \\
\hline $\mathrm{V}$ & $\begin{array}{l}\text { Convective drying enhanced with microwaves } \\
\text { throughout the process and IR periodically. The } \\
\text { whole process consists of } 6 \text { phases. The IR radiation } \\
\text { was applied only in phases } 1,3 \text { and } 5 \text {. The length of } \\
\text { these phases was controlled by the temperature of } \\
\text { the sample surface, a phase was terminated when } \\
\text { the predetermined temperature was reached } \\
\left(333.15 \mathrm{~K} \text {, i.e. } 60^{\circ} \mathrm{C} \text { in phase } 1 \text { and } 343.15 \mathrm{~K} \text {, i.e. } 70^{\circ} \mathrm{C}\right. \\
\text { in phases } 3 \text { and } 5) . \text { In phases } 2 \text { and } 4(15 \text { min each) } \\
\text { and } 6 \text { ( } 60 \text { min) the microwave-assisted convective } \\
\text { drying was performed }\end{array}$ \\
\hline
\end{tabular}
average.
Table 1. Description of drying procedure

The balance, type WPS 2100/C/1 (precision $0.01 \mathrm{~g}$ ) produced by Radwag (Radom, Poland), was used for constant measurement of the sample mass reduction. The temperature of the sample surface was measured by the pyrometer, model $\mathrm{MI}$ (precision $1^{\circ}$ ), produced by Raytek (Santa Cruz, CA, USA), placed in the corner of the drying chamber. The pyrometer is a noncontact device that intercepts and measures thermal radiation emitted by the material. Air velocity was measured with the use of a hotwire anemometer, model CTV 100 (precision $0.1 \mathrm{~m} / \mathrm{s}$ ), produced by KIMO (Montpon, France). All of the measured parameters, such as mass and temperature of the sample, airflow velocity, temperature or humidity, reflected microwave power, etc., were recorded every $5 \mathrm{~s}$ during the whole process and stored in the standard personal computer equipped with the data acquisition software provided with the dryer.

Kinetics of each process was analysed on the basis of drying curves - evolution of the moisture ratio in time. The moisture ratio (MR) was designated from the following equation:

$$
\mathrm{MR}=\left(\mathrm{MC}_{\mathrm{t}}-\mathrm{MC}_{\mathrm{eq}}\right) /\left(\mathrm{MC}_{\mathrm{i}}-\mathrm{MC}_{\mathrm{eq}}\right)
$$

where $\mathrm{MC}_{\mathrm{i}}, \mathrm{MC}_{\mathrm{t}}$ and $\mathrm{MC}_{\mathrm{eq}}$ are initial, current (at a given time of process) and equilibrium moisture content, respectively.

Initial moisture content $\left(\mathrm{MC}_{\mathrm{i}}\right)$ of the material was determined with the moisture analyser model XM120 (precision $0.01 \%$ ), produced by Precisa (Dietikon, Switzerland). Equilibrium moisture content $\left(\mathrm{MC}_{\mathrm{eq}}\right)$ was assumed constant during the research and equalled $5 \%$. Moisture content at a given time of the process $\left(\mathrm{MC}_{\mathrm{t}}\right)$ was expressed as the ratio of moisture mass $\left(m_{\mathrm{m}}\right)$ to the initial mass of wet sample $\left(m_{\mathrm{i}}\right)$ according to the formula:

$$
\mathrm{MC}_{\mathrm{t}}=m_{\mathrm{m}} / m_{\mathrm{i}}=\left(m_{\mathrm{i}}-m_{\mathrm{s}}\right) / m_{\mathrm{i}}
$$

where $m_{\mathrm{s}}$ is the mass of dry matter and refers to $m_{\mathrm{si}}$ of samples not processed with osmotic dehydration and $m_{\mathrm{st}}$ of samples processed with osmotic dehydration with or without ultrasound assistance, respectively. 


\section{Quality assessment of products}

Product quality was judged on the basis of colorimetric measurements and sensory analysis of shape, texture and smell.

The colour of the fresh and dried samples was measured with the CR400 colorimeter (illuminant D65, observer $2^{\circ}$, precision 0.01 ) produced by Konica Minolta (Tokyo, Japan) and expressed in CIELab colour space. Before measurements, the samples were ground with the use of laboratory mill, model Basic produced by IKA (Königswinter, Germany), and the colorimeter was calibrated on a special white plate. Each test was carried out in standardised sample holder to provide identical measurement conditions and eliminate the influence of background and surroundings. Measurements of colour parameters $\left(L^{*}, a^{*}\right.$ and $\left.b^{*}\right)$ were conducted ten times in two randomly chosen measuring points (20 measurements per sample). Next, the arithmetic mean was calculated and the differences in sample colour (before and after drying) were assigned as a relative colour change parameter $\mathrm{d} E$ according to the following equation:

$$
\begin{gathered}
\mathrm{d} E=\left(\Delta L^{* 2}+\Delta a^{* 2}+\Delta b^{* 2}\right)^{0.5}= \\
\left(\left(L_{\mathrm{i}}^{*}-L_{\mathrm{t}}^{*}\right)^{2}+\left(a_{\mathrm{i}}^{*}-a_{\mathrm{t}}^{*}\right)^{2}+\left(b_{\mathrm{i}}^{*}-b_{\mathrm{t}}^{*}\right)^{2}\right)^{0.5}
\end{gathered}
$$

where index $i$ refers to the initial values of colour coordinates measured on fresh (not processed) samples and index $t$ denotes values of colour parameters measured on dried material.

\section{Statistical analysis}

Each of the analysed processes was performed in triplicate. The obtained data were averaged and the standard deviation was calculated. All computations were made with Statistica v. 12 software delivered by StatSoft (Kraków, Poland).

\section{Results and Discussion}

\section{Kinetics of the osmotic dehydration}

In the first part of the study, the osmotic dehydration kinetics with and without ultrasound assistance was analysed. For this purpose, samples of carrots were dehy- drated in fructose solution $(w=400 \mathrm{~g} / \mathrm{kg})$ for $120 \mathrm{~min}$ at constant temperature of $303.15 \mathrm{~K}\left(30^{\circ} \mathrm{C}\right)$. On the basis of mass loss measurements, the osmotic dehydration rate, solid gain and water loss were determined (Fig. 1).

The course of dehydration curves of both processes was very similar (Fig. 1a). At the beginning, the dehydration rate increased rapidly and reached its maximum in about $15-20 \mathrm{~min}$, then it started to fall slowly, and in 120 min reached the value equal to 0 during osmotic dehydration or close to 0 during ultrasound-assisted osmotic dehydration. Application of ultrasound affected all considered kinetic parameters. Dehydration rate during ultrasound-assisted osmotic process obtained higher values than those observed during simple osmosis without ultrasound enhancement. Moreover, solid gain and water loss were also visibly higher when the osmosis was supported with ultrasound (Fig. 1b).

Higher values of osmotic dehydration rate and water loss may result from mechanical effects of ultrasound due to the sponge effect or cavitation phenomenon as well as reduction of the laminar boundary sublayer. These phenomena lead to an increase in water diffusivity (mass transfer intensification) and thus higher water loss during dehydration. In turn, the increase of the solid uptake in ultrasonically assisted processes can be a consequence of the modification of cell structure through an action of ultrasound waves. As it was stated in the respective literature (33-35), ultrasonic waves may cause a breakdown in the biomaterial structure, coherence loss or even cell disruption. As an effect, the solute can penetrate more easily the material causing higher solid uptake.

The obtained results lead to a conclusion that the most effective period of osmotic dehydration, regardless of the ultrasound assistance, took place during the first 30 min of the operation. For this reason, the time of dehydration was fixed at 30 min during further studies.

Fig. $1 \mathrm{~b}$ shows the average values of solid gain and water loss determined after $30 \mathrm{~min}$ of dehydration. It can be easily noticed that, despite shorter dehydration time, once again both considered parameters obtained higher values during ultrasonically assisted process. Such results confirm positive influence of ultrasound addition on dehydration process. The overall magnitude of the analysed parameters was in this case visibly smaller than that ob-
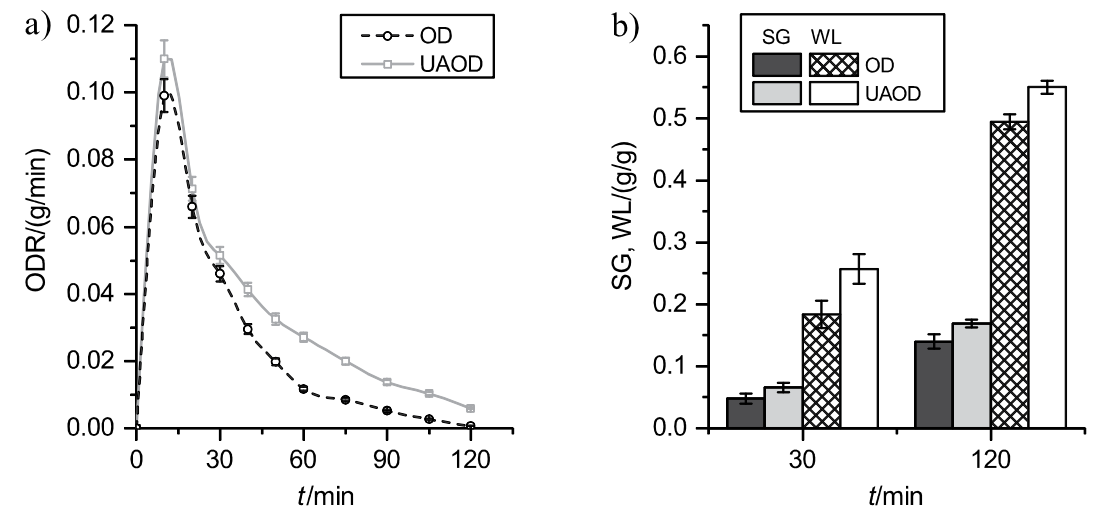

Fig. 1. Kinetics of dehydration: a) osmotic dehydration rate (ODR), b) solid gain (SG) and water loss (WL) determined on wet basis during experiments. $\mathrm{OD}=$ osmotic dehydration, $\mathrm{UAOD}=$ ultrasound-assisted osmotic dehydration 
served previously (during 120-minute dehydration), which is the consequence of the significantly shorter pretreatment time.

\section{Kinetics of the final drying stage}

After osmotic pretreatment, initially dehydrated samples were dried in laboratory hybrid dryer (31) in accordance with the schedules described in Table 1. Each drying procedure was carried out in three steps: (i) drying of the raw samples (control), (ii) drying of the samples processed with the osmotic solution, and (iii) drying of the samples pretreated with the ultrasound-assisted osmotic process. Drying curves for convective and microwave-assisted convective processes are shown in Fig. 2.

Comparison of the curves obtained for control procedure shows that the application of microwaves influenced significantly the convective drying kinetics. Drying time in procedure II was almost threefold shorter, which implies a significantly higher rate of drying than in procedure I. Such phenomenon resulted from two unusual attributes of microwave radiation. Firstly, microwaves are the efficient source of energy that can heat up the moist material to a very high temperature in a very short time. Secondly, the heat is generated in the whole volume of the sample exposed to the microwaves, unless its dimensions are bigger than the depth of the microwave penetration. In this way, the fundamental kinetic constraints of the convective processes may be overcome and the drying operation may be completed considerably faster.

Analysis of the curves obtained during drying of samples processed with osmosis (Fig. 2) leads to a conclusion that initial osmotic pretreatment slightly influenced the convective drying kinetics and did not affect the microwave-assisted convective process. Although in convective drying (procedure I) a slight reduction of drying time of the samples dehydrated with osmosis was observed, this was not observed during procedure II. Application of ultrasound during osmotic dehydration did not influence the drying kinetics either. Regardless of the pretreatment method, the drying time was similar and the observed aberrations were small enough to be neglected. This may result from solute uptake during osmotic dehydration. Soluble solids probably blocked the pores and hindered the moisture transfer during drying. In Fig. 3 the evolu- tion of moisture ratio during procedures III, IV and V is presented.

Application of microwaves during the first $40 \mathrm{~min}$ of drying in procedure III (Fig. 3a) was aimed at the improvement of product quality. In previous works $(31,32)$ authors found that long exposure to microwave radiation may lead to several negative effects such as local overheating (hot spots), thermal degradation of nutrients, colourants and proteins, excessive deformation and shrinkage. To avoid these negative effects in the procedure III, the convective process was enhanced with microwaves only for the first $40 \mathrm{~min}$.

Obviously, shorter microwave irradiation influenced the convective drying kinetics. Drying time was, in this case, longer than in microwave-assisted convective drying (procedure II), but still shorter than only convective drying (procedure I).

Furthermore, in contrast to previous drying procedures, there was a pronounced effect of osmotic pretreatment on the kinetics of the final drying process. Samples dehydrated by osmosis dried significantly faster, whereas specimens processed with ultrasonic assistance dried slightly slower than in control process. The reason for this phenomenon has not been known yet, but it is assumed that slower post-drying of samples processed with ultrasound-assisted osmotic dehydration may result from higher solid uptake during osmosis. This explanation stays in good agreement with the conclusions drawn from comparative analysis of drying kinetics of samples pretreated with and without ultrasound assistance. The drying time of samples pretreated with ultrasound (higher solid gain) was also longer than of samples processed with simple osmosis (lower solid gain).

In procedure IV convective drying was enhanced with microwaves after the 120th min of the convective process (Fig. 3b). Application of microwaves was in this case aimed at acceleration of the slowest part of drying, the so-called falling rate period or second period of drying. During this part of the process, the drying rate is fully controlled by the diffusion of the moisture inside the material being dried (internal resistance). Intensification of process conditions (e.g. application of higher temperature or faster flow velocity) does not affect overall drying rate because the rate of operation is fully controlled by
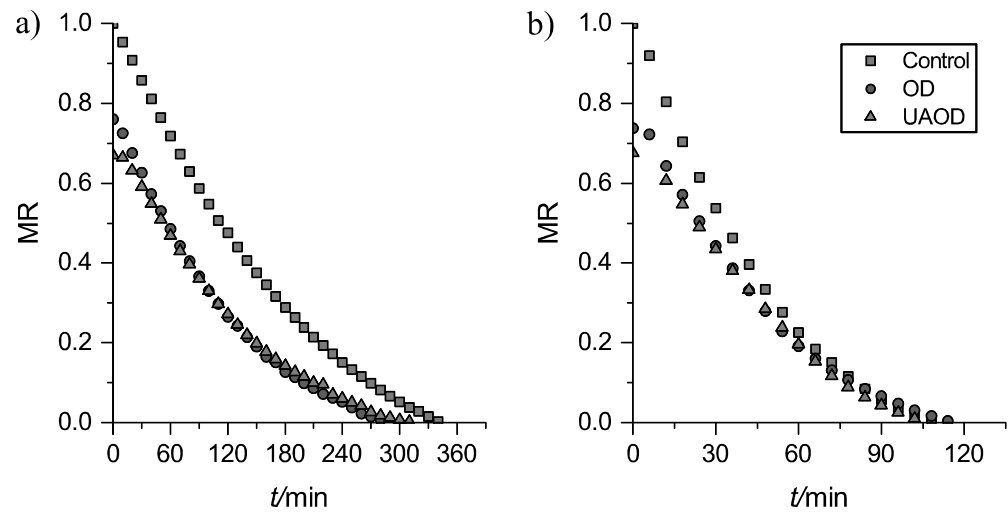

Fig. 2. Evolution of the moisture ratio (MR) during: a) convective (procedure I) and b) microwave-assisted convective drying (procedure II). $\mathrm{OD}=$ osmotic dehydration, $\mathrm{UAOD}=$ ultrasound-assisted osmotic dehydration 

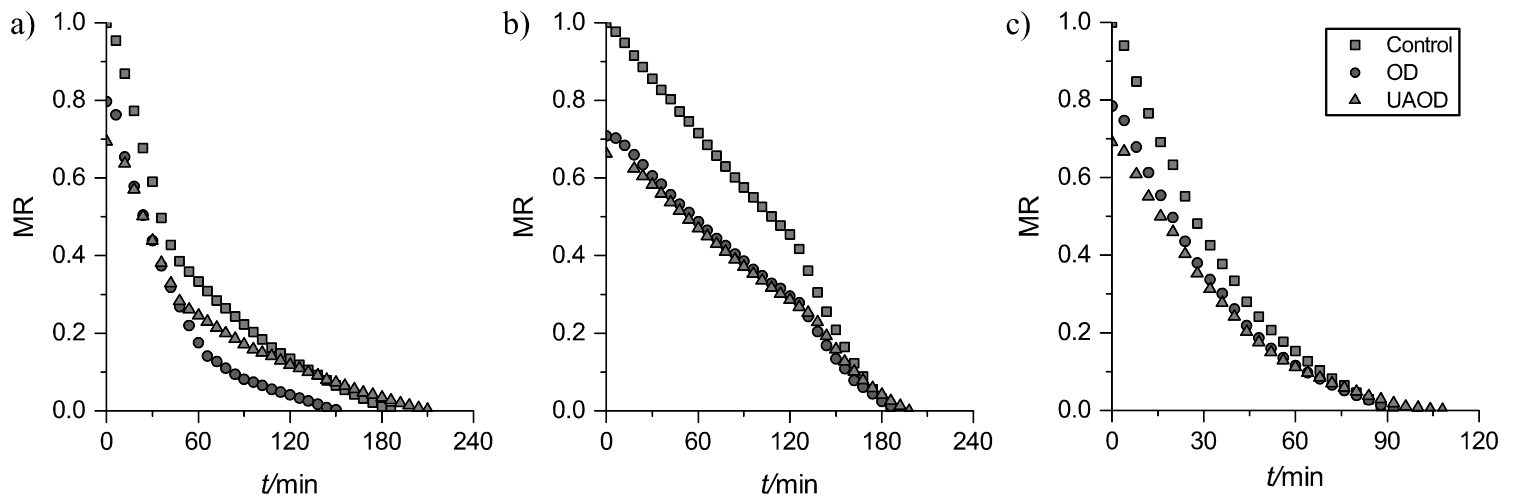

Fig. 3. Evolution of the moisture ratio (MR) during: a) convective drying enhanced with microwaves during the first 40 min of the process (procedure III), b) convective drying enhanced with microwaves after the 120th min of the process (procedure IV), and c) microwave-assisted convective drying enhanced periodically with IR (procedure V). OD=osmotic dehydration, UAOD=ultrasound-assisted osmotic dehydration

diffusion inside the samples. Microwaves may be used to overcome this constraint due to their ability to evaporate the moisture inside the material and hasten its movement to the surface, both in vapour and liquid state $(31,32)$.

The action of microwaves brought the desired effect. However, the drying time during procedure IV was visibly longer than during simple microwave-assisted convective drying (procedure II) but significantly shorter than convective process (procedure I). It is an economically efficient process (lower energy consumption) resulting in better product quality (higher value of products). Besides, the influence of osmotic pretreatment was found as neither positive nor negative. Post-drying time of pretreated samples was similar to control process apart from the different methods of dehydration (with or without ultrasound).

The last and the most complex drying process (procedure V) incorporated all three techniques, namely convection, microwaves and infrared radiation (IR). The convective drying was in this case enhanced with microwaves during the whole process and periodically with infrared radiation. The application of IR was aimed at evaporation of moisture present on the surface of the material being dried. It was observed that a very thin layer of water is present on the surface of the biological material rich with moisture at the beginning of the drying. Therefore, it is reasonable to use an efficient source of heat to evaporate this layer and accelerate the overall drying. For this reason, thermal radiation as one of the most effective sources of heat energy that can be easily transferred to the material was periodically used during the fifth drying procedure.

Simultaneous action of all three drying techniques caused a significant increase of the drying rate and reduction in operational time (Fig. 3c). In effect, this drying process becomes the fastest one of all analysed procedures. Drying time was reduced from the longest period of convective drying by $73 \%$.

Such a great achievement follows from a complementary action of all three drying techniques. Microwaves heat up the interior of the sample, lowering the temperature gradients and accelerating the moisture movement from the interior to the surface. IR efficiently evaporates the moisture 'pushed' by microwaves to the surface. Hot air flowing around the samples carries off the evaporated moisture and transfers it to the surroundings. The obtained results prove that properly planned hybrid processes allow saving valuable drying time, which may also lead to the reduction of consumed energy. From the economic point of view, this advantage is not underestimated in industrial applications.

Neither positive nor negative effects of the osmotic pretreatment on the drying kinetics were observed (Fig. 3c). The drying time of samples dehydrated without ultrasound was similar to the control process, whereas samples dehydrated with the ultrasound assistance were dried slightly longer than both reference processes (control and osmotic dehydration). Such results may follow from the aforementioned difference in solid uptake during osmosis.

\section{Quality of obtained products}

The quality of the examined products was assessed through colorimetric measurements and sensory analysis of shape, texture and smell. In Fig. 4 the relative colour change parameter $(\mathrm{d} E)$ determined in accordance with Eq. 6 for particular procedures of drying is presented.

The colour change parameter allows assessing how the colour of dried products differs from the original colour of fresh samples. This parameter is actually a vector connecting two points in three-dimensional space. The higher the value of $\mathrm{d} E$ (longer vector), the more visible the difference between the compared colours (greater distance between two points).

It can be seen that the highest values of $\mathrm{d} E$ occurred in convective and microwave-assisted convective drying. In the first case the considerable change of colour results from long drying time at a relatively high temperature, which leads to the decomposition of thermolabile natural colorants and other chemical and biochemical reactions (e.g. Maillard reaction, enzymatic and non-enzymatic browning, etc.). In the second case, the colour degradation may result from high temperatures occurring in the material due to microwave radiation. Although 


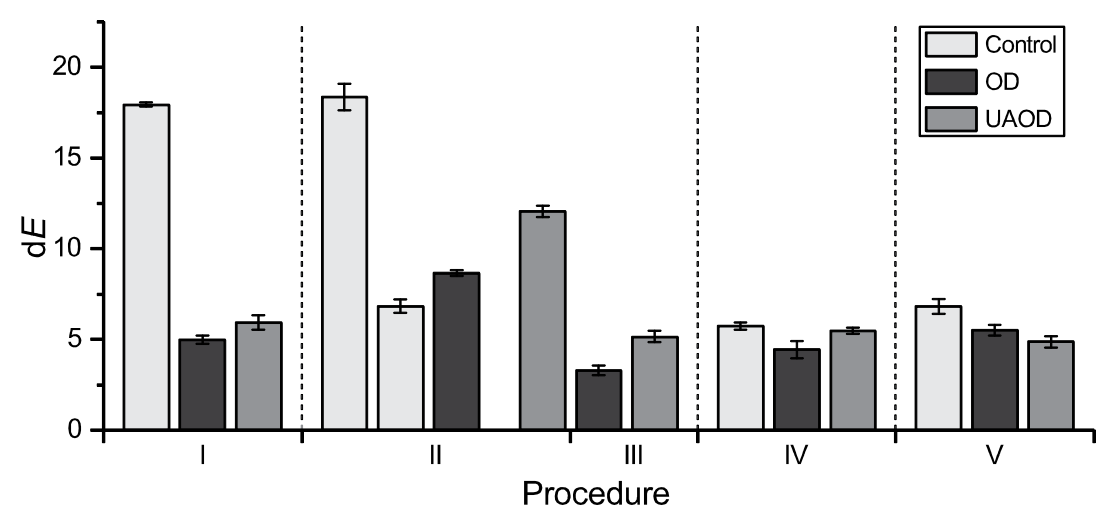

Fig. 4. Relative colour change parameter $(\mathrm{d} E)$ for particular drying procedure. $\mathrm{OD}=$ osmotic dehydration, $\mathrm{UAOD}=\mathrm{ultrasound}-\mathrm{assist}-$ ed osmotic dehydration

the air temperature was $328.15 \mathrm{~K}\left(55^{\circ} \mathrm{C}\right)$, the material temperature increased during the process even to a value of $338.15 \mathrm{~K}\left(65^{\circ} \mathrm{C}\right)$.

Microwave radiation is a very efficient source of energy which allows heating the material very rapidly. Unfortunately, during drying, dielectric properties of samples change (due to loss of moisture), which influences the microwave absorptivity of the material and thus the efficiency of the process. At the beginning when the material has relatively high moisture content, most of the delivered microwave energy is absorbed by the wet samples. When the vast majority of moisture has been removed, the microwave absorptivity of the material decreases and most of the delivered energy is dissipated. For this reason the application of constant microwave power during the whole process has no practical justification. The power of radiation should be adjusted to the moisture content of the material to provide similar irradiation conditions during the whole process (stable level of reflected power).

The colour of the samples dried with other procedures was affected to a significantly lesser degree. The lowest values of $\mathrm{d} E$ were observed in microwave-assisted convective drying, where the microwave radiation was applied for the first $40 \mathrm{~min}$ (procedure III) and after the 120th min of drying (procedure IV). The colour change had very positive effect because the reduction of microwave irradiation in these procedures was aimed at improvement of the product quality. Thus, it can be concluded that the intended goal was achieved with a relatively small extension of drying time in comparison with microwave-assisted convective drying (procedure II). What is also important, despite shortening of the microwave enhancement, both these procedures were still faster than pure convective drying.

A slight increase of the parameter $\mathrm{d} E$ in the drying procedure $\mathrm{V}$ results probably from the application of infrared radiation, which intensively heated up the sample surface. High instantaneous temperatures (330.15-340.15 $\mathrm{K}$ ) of the sample surface could cause a series of reactions that lead to changes in sample colour.

Analysis of colour change of pretreated samples shows that in the case of osmotic dehydration without ultrasound the colour was better preserved and the $\mathrm{d} E$ achieved distinctly smaller values than unprocessed specimens (control). The ultrasonically assisted pretreatment also positively influenced the colour of the samples, but in this case, the advantages were visibly fewer and the obtained $\mathrm{d} E$ values were slightly higher than of the samples processed without ultrasound.

This phenomenon may be explained by higher solid uptake, which may affect the sample colour. On the other hand, changes in the material structure, followed by the action of ultrasonic waves may also influence the quality parameters of the material. In our previous research $(15,16,36)$ the relationship between the amount of solute, which penetrates the material during osmosis, and the changes in the colour of the final products was found. Moreover, as it was stated in the literature $(7,37)$, the change of material structure (e.g. increased porosity) may affect the sensory parameters such as taste, texture and also colour.

Based on the sensory analysis, it was found that the products pretreated with osmosis better retained their original shape, smell and texture. The shrinkage and deformations were considerably smaller, the material surface was not rough or hard (improved tactile sensation) and the samples easily released the aroma even without rubbing. Differences in sensorial parameters after particular pretreatments followed by drying were difficult to observe and describe. However, it was found that the samples pretreated with ultrasound had the sweetest aroma in comparison with those dehydrated without ultrasound.

\section{Conclusion}

The results presented in this paper show that the ultrasound affects all the parameters of the osmotic dehydration kinetics. The positive influence of osmotic pretreatment on the kinetics of final drying was not found, apart from the pretreatment methods (with or without ultrasound) and drying procedures (convective, microwaves, hybrid, etc.). Nevertheless, the positive effect of osmotic dehydration on the quality of dried products was confirmed. Samples preliminary dehydrated with osmotic solution were better evaluated during the quality assessment. 
Hybrid techniques of drying were recognised as a promising alternative to conventional drying methods. Proper combination of the hot air drying with microwave and/or IR radiation allows faster drying with lower consumption of electricity. Despite the unquestionable advantages of hybrid processes, the technique is rarely studied in the literature, especially in combination with the osmotic pretreatment.

Utilisation of a special construction of the ultrasonic bath allows identifying the real impact of ultrasonic waves on the kinetics of osmosis. Thanks to the thermoregulatory system, the growth of the bath temperature due to the action of ultrasounds was not observed. Thus, the influence of temperature on the kinetics of osmosis may be neglected.

\section{Acknowledgements}

This work was carried out as part of research project no. PBS1/A8/13/2012, sponsored by the National Centre for Research and Development of Poland.

\section{References}

1. Krokida MK, Tsami E, Maroulis ZB. Kinetics on colour changes during drying of some fruits and vegetables. Dry Technol. 1998;16:667-85.

https://doi.org/10.1080/07373939808917429

2. Markowski M, Stankiewicz I, Zapotoczny P, Borowska J. Effect of variety on drying characteristics and selected quality attributes of dried carrots. Dry Technol. 2006;24:1011-18. https://doi.org/10.1080/07373930600776191

3. Santos PHS, Silva MA. Retention of vitamin C in drying processes of fruits and vegetables-a review. Dry Technol. 2008; 26:1421-37.

https://doi.org/10.1080/07373930802458911

4. Bonazzi C, Dumoulin E. Quality changes in food materials as influenced by drying processes. In: Tsotsas E, Mujumdar AS, editors. Modern drying technology, vol. 3: Product quality and formulation. Weinheim, Germany: Wiley-VCH Verlag GmbH \& Co KGaA; 2011. pp. 1-20. https://doi.org/10.1002/9783527631667.ch1

5. Ratti C. Shrinkage during drying of foodstuffs. J Food Eng. 1994;23:91-105. https://doi.org/10.1016/0260-8774(94)90125-2

6. Zogzas NP, Maroulis ZB, Marinos-Kouris D. Densities shrinkage and porosity of some vegetables during air drying. Dry Technol. 1994;12:1653-66. https://doi.org/10.1080/07373939408962191

7. Ramos IN, Brandão TRS, Silva CLM. Structural changes during air drying of fruits and vegetables. Food Sci Technol Int. 2003;9:201-6. https://doi.org/10.1177/1082013030335522

8. Strumiłło C, Jones PL, Żyłła R. Energy aspects in drying. In: Mujumdar AS, editor. Handbook of industrial drying. Boca Raton, FL, USA: CRC Press; 2006. pp. 1075-99.

9. Jangam SV, Mujumdar AS. Basic concepts and definitions. In: Jangam VS, Law CL, Mujumdar AS, editors. Drying of foods, vegetables and fruits, vol. 1. Singapore, Singapore; 2010. pp. 1-30.

10. Grabowski S, Marcotte M, Poirier M, Kudra T. Drying characteristics of osmotically pretreated cranberries - energy and quality aspects. Dry Technol. 2002;20:1989-2004.

https://doi.org/10.1081/DRT-120015580
11. Mujumdar AS. Research and development in drying: recent trends and future prospects. Dry Technol. 2004;22:1-26. https://doi.org/10.1081/DRT-120028201

12. Lenart A, Lewicki PP. Kinetics of osmotic dehydration of plant tissue. In: Mujumdar AS, editor. Drying '87, vol. 2. New York, NY, USA: Hemisphere Publisher; 1987. pp. 239-48.

13. Pan YK, Zhao LJ, Zhang Y, Chen G, Mujumdar AS. Osmotic dehydration pretreatment in drying of fruits and vegetables. Dry Technol. 2003;21:1101-14. https://doi.org/10.1081/DRT-120021877

14. Torreggiani D. Osmotic dehydration in fruit and vegetable processing. Food Res Int. 1993;26:59-68. https://doi.org/10.1016/0963-9969(93)90106-S

15. Kowalski SJ, Mierzwa D, Śronek B. Drying of osmotically dehydrated biological materials. Chem Process Eng. 2009;30: 559-68.

16. Kowalski SJ, Mierzwa D. Influence of preliminary osmotic dehydration on drying kinetics and final quality of carrot (Daucus carota L.). Chem Process Eng. 2011;32:185-94. https://doi.org/10.2478/v10176-011-0014-6

17. Lewicki PP, Lenart A. Osmotic dehydration of fruits and vegetables. In: Mujumdar AS, editor. Handbook of industrial drying. Boca Raton, FL, USA: CRC Press; 2006. pp. 665-88.

18. Mohebbi M, Shahidi F, Fathi M, Ehtiati A, Noshad M. Prediction of moisture content in pre-osmosed and ultrasounded dried banana using genetic algorithm and neural network. Food Bioprod Process. 2011;89:362-6. https://doi.org/10.1016/j.fbp.2010.08.001

19. García-Pérez JV, Cárcel JA, Benedito J, Mulet A. Power ultrasound mass transfer enhancement on food drying. Food Bioprod Process. 2007;85:247-54. https://doi.org/10.1205/fbp07010

20. Cárcel JA, Benedito J, Rosselló C, Mulet A. Influence of ultrasound intensity on mass transfer in apple immersed in a sucrose solution. J Food Eng. 2007;78:472-9. https://doi.org/10.1016/j.jfoodeng.2005.10.018

21. Rodrigues S, Fernandes FAN. Use of ultrasound as pretreatment for dehydration of melons. Dry Technol. 2007;25:17916. https://doi.org/10.1080/07373930701595409

22. de la Fuente-Blanco S, Riera-Franco de Sarabia E, AcostaAparicio VM, Blanco-Blanco A, Gallego-Juárez JA. Food drying process by power ultrasound. Ultrasonics. 2006;44:e5237. https://doi.org/10.1016/j.ultras.2006.05.181

23. Wong E, Vaillant F, Pérez A. Osmosonication of blackberry juice: impact on selected pathogens spoilage microorganisms and main quality parameters. J Food Sci. 2010;75:M46874 . https://doi.org/10.1111/j.1750-3841.2010.01730.x

24. Wong E, Vaillant-Barka F, Chaves-Olarte E. Synergistic effect of sonication and high osmotic pressure enhances membrane damage and viability loss of Salmonella in orange juice. Food Res Int. 2012;45:1072-9. https://doi.org/10.1016/j.foodres.2010.07.037

25. Costa C, Antonucci F, Pallottino F, Aguzzi J, Sun DW, Menesatti P. Shape analysis of agricultural products: a review of recent research advances and potential application to computer vision. Food Bioprocess Technol. 2011;4:673-92. https://doi.org/10.1007/s11947-011-0556-0

26. Priluck Grossman R, Wisenblit JZ. What we know about consumers' colour choices. J Marketing Pract: Appl Marketing Sci. 1999;5:78-88. https://doi.org/10.1108/EuM0000000004565

27. Pathare PB, Opara UL, Al-Said FAJ. Colour measurement and analysis in fresh and processed foods: a review. Food 
Bioprocess Technol. 2013;6:36-60.

https://doi.org/10.1007/s11947-012-0867-9

28. Pereira AC, Reis MS, Saraiva PM. Quality control of food products using image analysis and multivariate statistical tools. Ind Eng Chem Res. 2009;48:988-98. https://doi.org/10.1021/ie071610b

29. León K, Mery D, Pedreschi F, León J. Colour measurement in $L^{*} a^{*} b^{*}$ units from RGB digital images. Food Res Int. 2006; 39:1084-91.

https://doi.org/10.1016/j.foodres.2006.03.006

30. Francis FJ. Quality as influenced by colour. Food Qual Prefer. 1995;6:149-55. https://doi.org/10.1016/0950-3293(94)00026-R

31. Kowalski SJ, Mierzwa D. Convective drying in combination with microwave and IR drying for biological materials. Dry Technol. 2009;27:1292-301. https://doi.org/10.1080/07373930903207712

32. Kowalski SJ, Mierzwa D. Hybrid drying of red bell pepper: energy and quality issues. Dry Technol. 2011;29:1195-203. https://doi.org/10.1080/07373937.2011.578231
33. Fernandes FAN, Gallão MI, Rodrigues S. Effect of osmosis and ultrasound on pineapple cell tissue structure during dehydration. J Food Eng. 2009;90:186-90.

https://doi.org/10.1016/j.jfoodeng.2008.06.021

34. Fernandes FAN, Gallão MI, Rodrigues S. Effect of osmotic dehydration and ultrasound pre-treatment on cell structure: melon dehydration. LWT - Food Sci Technol. 2008;41:604-10. https://doi.org/10.1016/j.lwt.2007.05.007

35. Rodrigues S, Gomes MCF, Gallão MI, Fernandes FAN. Effect of ultrasound-assisted osmotic dehydration on cell structure of sapotas. J Sci Food Agr. 2009;89:665-70. https://doi.org/10.1002/jsfa.3498

36. Kowalski SJ, Mierzwa D. Influence of osmotic pretreatment on kinetics of convective drying and quality of apples. Dry Technol. 2013;31:1849-55.

https://doi.org/10.1080/07373937.2013.833518

37. Oikonomopoulou V, Krokida M, Karathanos V. Influence of structure on saltiness and sweetness of dehydrated food products. Dry Technol. 2013;31:837-47. https://doi.org/10.1080/07373937.2013.768265 